\title{
Intact implicit and reduced explicit memory for negative self-related information in repressive coping
}

\author{
ESTHER FuJIWARA \\ Rotman Research Institute, Baycrest Centre, Toronto, Ontario, Canada \\ AND \\ Brian Levine ANd Adam K. Anderson \\ Rotman Research Institute, Baycrest Centre, Toronto, Ontario, Canada \\ and University of Toronto, Toronto, Ontario, Canada
}

\begin{abstract}
Voluntary emotional memory control has recently been shown to involve prefrontal down-regulation of medial temporal lobe activity during memory retrieval. However, little is known about instances of uninstructed, naturally occurring forgetting. In the present study, we examined whether memory suppression extends to involuntary, uninstructed down-regulation of memory in individuals thought to be experts in forgetting negative memories - those with a repressive coping style. We contrasted explicit and implicit memory for negative information in repressor and nonrepressor groups and examined whether self-relevance is a moderating variable. To delineate the specificity of repressors' selective memory reductions, we contrasted encoding and retrieval of emotional words as a function of self-reference, subjective self-relevance, and explicitness of the memory task in nonrepressors and repressors. Self-descriptiveness judgments, lexical decisions (implicit memory), and free recall (explicit memory) were investigated. Repressors had selectively lowered free recall only for negative, self-relevant information. Their implicit memory for the same information was unaffected. This pattern suggests that regulation of emotional memory in repressive individuals is a case of motivated forgetting, possibly sharing much of the neural underpinnings of voluntary memory suppression.
\end{abstract}

M. C. Anderson and Green (2001) showed that people are well able to forget certain memories when they are told to forget them. Forgetting was associated with enhanced prefrontal control decreasing memory-related medial temporal lobe activity during retrieval in an explicit associative memory task (M. C. Anderson et al., 2004). Similar neural mechanisms were reported in instructed forgetting of emotional materials (Depue, Curran, \& Banich, 2007). An important open question is whether instructing people to suppress emotional memories is a valid model of naturally occurring forgetting. By contrasting explicit and implicit memory, we considered two possible mechanisms in natural emotional memory control: If forgetting affects only explicit memory, where strategic control over memory output can be exerted, this would imply behavioral and neural similarity between instructed and uninstructed emotional memory control. Alternatively, if forgetting extends also to implicit memory, with little or no opportunity for conscious control, this would suggest fundamentally different mechanisms for instructed and for naturally occurring forgetting.

Individuals with a repressive coping style provide a model population to study naturally occurring forgetting of negative memories (e.g., Davis \& Schwartz, 1987). Central to the assumption of repression as a defense (Freud, 1915/1957) is that it serves to minimize feelings of anxiety associated with certain thoughts and behaviors. In the individual differences literature on repressive coping style (e.g., Weinberger, Schwartz, \& Davidson, 1979), repressors are assumed to be unaware of their true anxiety levels (despite autonomic evidence for high anxiety and consistent with repression being a form of self-defense; Weinberger et al., 1979). Consequently, one dimension of the common classification scheme differentiating repressors from nonrepressors focuses on elevated scores in measures of social desirability in repressors (i.e., overly positive self-presentation), whereas the other dimension concerns anxiety. Thus, the concept of dispositional repressiveness suggests that repressors present themselves in an overly positive way (high social desirability) and report few negative traits (low anxiety) (see the Participants section for more details).

On the basis of previous findings, repressors may show neural and behavioral differences from nonrepressor groups at both early and late information processing stages. However, thus far, no conclusive prediction can be 
made relating early neural processes of perception/attention to later memory. The few prior neuroimaging studies investigating variants of the repressive coping style (Rauch et al., 2007; Sander, Roth, \& Scheich, 2003) have addressed perceptual processing of emotional stimuli. These studies found neural differences between repressors and nonrepressors. For instance, in a passive viewing task, Rauch and colleagues found that repressors (compared with nonrepressors) had enhanced lateral prefrontal recruitment and less amygdala activity during unmasked face presentations. Furthermore, repressors showed enhanced recruitment of visual and anterior cingulate cortex areas during masked presentation of fearful facial expressions. Thus, repressors showed differences in brain activity in sensory and control-related brain regions even in conditions of relative unawareness. Thus, one might assume that repressors will exert enhanced control over implicit processing of negative information.

Similar behavioral evidence for early alterations of information processing comes from attention studies with repressors, showing attentional avoidance of threat in repressors (in emotional dot-probe tasks [Fox, 1994; Ioannou, Mogg, \& Bradley, 2004] and emotional Stroop tasks [Myers \& McKenna, 1996; Newman \& McKinney, 2002]). Hansen and Hansen (1988) argued that repressors selectively attend only to the most salient emotional features of information while disregarding secondary emotional connotations. Such initial oversimplification may result in repressors' less elaborate encoding of emotional memories, which should then also be more difficult to retrieve (see Schimmack \& Hartmann, 1997, for an alternate explanation). There is much evidence for memory reductions in repressors. Repressors seem especially impaired in explicit retrieval of negative autobiographical memories (Davis, 1990; Davis \& Schwartz, 1987; Myers \& Brewin, 1994; Newman \& Hedberg, 1999). However, when we try to tease apart effects at encoding from effects at retrieval, most evidence points to selective effects at memory retrieval, not at encoding (Holtgraves \& Hall, 1995; Myers \& Derakshan, 2004; Shane \& Peterson, 2004). When we combine this evidence, we are faced with a paradox: Repressors seem to selectively avoid attending negative information, but their memory reductions seem to affect retrieval, not encoding.

Depue et al. (2007) observed that early in their instructed forgetting training, hippocampal activity was greater for later to-be-forgotten than for to-be-remembered items. This result, similar to what M. C. Anderson et al. (2004) observed, implies that in order to forget a memory, one first has to retrieve it. In natural forgetting, similar processes may apply: Information that is subject to forgetting should be stored and remain accessible, possibly to guide later forgetting. One way of showing this would be to find intact implicit memory in the face of reduced explicit memory. Prior memory research in repressors has been dominated by explicit memory tasks, allowing participants to make strategic retrieval decisions. Surprisingly, implicit memory has very rarely been studied in repressors and the results have been inconclusive (Jansson, Lundh, \& Oldenburg, 2005; Oldenburg, Lundh, \& Kivisto, 2002). Since implicit memory tasks do not require participants to deliberately reproduce potentially unwanted information, they are ideally suited to assess memory content without confounding volitional interference during retrieval. By directly comparing encoding, implicit memory retrieval, and explicit memory retrieval, we sought to clarify where along the information processing stream selective avoidance effects are most evident in repressors. We suggest two alternate hypotheses: (1) In line with recent work on the neural bases of how people suppress unwanted memories when instructed to forget them (M. C. Anderson et al., 2004; Depue et al., 2007), prefrontally mediated voluntary memory suppression may also be present in naturally occurring forgetting. Thus, if repressors are deliberately reducing certain memories, they should show reduced explicit but intact implicit memory. We could then assume similar prefrontal control processes influencing medial temporal lobe activity in instructed and naturally occurring forgetting. (2) Alternatively, if repressors have a highly automated avoidance of negative information (i.e., if they are forgetting experts), as is suggested by previous results of early neural differences between repressors and nonrepressors (Rauch et al., 2007), their forgetting should extend also to implicit memory. Such an outcome would suggest a fundamental difference between instructed and naturally occurring forgetting. Then, in addition to enhanced prefrontal control over medial temporal lobe activity, naturally occurring forgetting may be associated with reduced cortical repetition suppression (cf. Buckner \& Koutstaal, 1998). Here we provide a behavioral test of these two alternatives.

To trigger natural forgetting most effectively while maintaining repressors' natural information processing routines, we presented emotional stimuli in two incidental encoding conditions: self-reference judgments and semantic comparison judgments. Assuming that repression serves selfprotective purposes (Freud, 1915/1957; Weinberger et al., 1979), repressors should show selective memory biases against negative information from a self-referent context (Myers, Brewin, \& Power, 1998; Myers \& Derakshan, 2004) - that is, a pattern opposite to the self-reference effect in memory (cf. Symons \& Johnson, 1997). Without directed-forgetting instructions (such as in Myers et al., 1998; Myers \& Derakshan, 2004), presentation of negative information in a self-referent context alone may be too weak to trigger natural forgetting in repressors. Thus, we carried out the following analyses: We first analyzed repressors' implicit and explicit memory for negative information encoded in a self-reference task compared with a semantic judgment task. Then, within the self-reference task, we examined whether subjective judgments of selfrelevance modulated memory in repressors.

\section{METHOD}

\section{Overview}

Participants were tested in a single 2-h session. Each session contained personality assessment and four experimental tasks, in a fixed order. In the first task, participants judged positive- and negativetrait words with regard to self-descriptiveness or emotional valence. In the second task, implicit memory for these items was assessed with a lexical decision task. Third, we tested explicit memory with a 
free recall task. Finally, a recognition task was carried out after free recall. The recognition results are not presented here.

\section{Participants}

Participants were first-year psychology students. Participants received the first 10 items of the Balanced Inventory of Desirable Responding (BIDR; Paulhus, 1991) in a prior mass testing session. These items are part of the BIDR subscale that measures self-deceptive enhancement (SDE). From a total of 1,636 participants, we selected 680 native English speakers with valid questionnaire data and contact information. On the basis of their continuous scores in the shortened $\mathrm{SDE}$, we performed quartile splits. We subdivided the group into potential repressor participants (upper $25 \%$ of scores in the shortened SDE) and nonrepressor participants (lower 25\% shortened SDE scores) and then contacted the resulting 409 individuals by phone. Participants were told that the experiment was designed to explore how personality influences people's attention to emotional words. Of the original 409 contacted individuals, a total of 103 students $(62$ females, 41 males) agreed to participate in the study in partial fulfillment of a course requirement. In the test session, participants were given two questionnaires: the entire BIDR (Paulhus, 1991) and the Bendig short version of the Taylor Manifest Anxiety Scale (Bendig, 1956). Partial BIDR scores from mass testing were used for purposes of preselection but were not used in the experiment.

The most common way of selecting repressors is the categorical classification suggested by Weinberger (1990) and Weinberger et al. (1979), which combines two questionnaire measures: low self-reported anxiety (e.g., Bendig's version of the Taylor Manifest Anxiety Scale; Bendig, 1956) and high social desirability - that is, denial of common, but undesirable behaviors and overly optimistic beliefs of self-control (commonly, Marlow-Crowne Social Desirability Scale; Crowne \& Marlowe, 1964). We employed the SDE scale of the BIDR (Paulhus, 1991) to assess the desirability dimension of the repressive coping style construct. The BIDR is a 40 -item questionnaire with two separate 20 -item subscales assessing different aspects of desirable responding: SDE and impression management (IM). SDE assesses self-deception regarding personal control and vulnerability (e.g., "I am fully in control of my own fate"; "I don't care to know what other people really think of me"), whereas IM measures denial of socially undesirable behaviors (e.g., "I always declare everything at customs"; "I have never dropped litter on the street"). The BIDR has only recently been used in the repressive coping style literature (e.g., Ashley \& Holtgraves, 2003; Shane \& Peterson, 2004), instead of the Marlowe-Crowne Social Desirability Scale (Crowne \& Marlowe, 1964). Repressors need to convince themselves and not just others of their own invulnerability against anxiety (Weinberger et al., 1979). Thus, the SDE part of the BIDR is more directly related to the repressive coping style than the Marlowe-Crowne Social Desirability Scale, subsuming inward- and outward-directed deception in one measure (see also Ashley \& Holtgraves, 2003). When scored continuously, responses in the 20 items of the SDE scale of the BIDR are measured with a 7-point scale, with a maximum score of 140 .

The Bendig short version of the TMAS (Bendig, 1956) was also administered. This anxiety questionnaire contains 20 true-false statements (maximum score 20 points) and has been widely used in classification of repressive and nonrepressive individuals, because repressors should report low anxiety, associated with their self-deception.

Using criteria similar to those suggested by Weinberger (1990), participants were subdivided into four groups, on the basis of median splits of their scores in both the TMAS and SDE: repressor (low anxiety-high defensiveness), low anxious (low anxiety-low defensiveness), high anxious (high anxiety-low defensiveness), and defensive high anxious (high anxiety-high defensiveness). ${ }^{1}$ Median splits for TMAS and SDE were 9 and 79 points, respectively. This resulted in 34 repressor ( $n=19$ males), 20 low-anxious ( $n=7$ males), 32 high-anxious ( $n=11$ males), and 17 defensive high-anxious participants ( $n=4$ males). Since the number of male participants was unequal between groups $\left(\chi^{2}=8.32, p<.01\right)$, we included gender as an additional factor in all analyses.

\section{Materials}

Words and nonwords. A total of 200 personality trait adjectives (100 positive, 100 negative words) were drawn from a commonly used database of likeableness ratings (N. H. Anderson, 1968). Positive and negative words were equated in length (3-10 letters), statistical frequency (available for most of the words), and meaningfulness. For the lexical decision task, 200 pronounceable nonword letter strings were constructed. Words and nonwords were equated in length.

\section{Tasks}

The judgment task and lexical decision task were administered with Presentation software (version 10.0; www.neurobs.com) on standard desktop computers.

Encoding: Judgment task. For each individual, a subset of 50 positive and 50 negative words was randomly chosen from the pool of 200 target words. Participants were instructed to judge a word as descriptive of oneself or not (self instruction) or to judge whether a word had a positive or negative connotation (valence instruction). A left keypress indicated self-descriptiveness after self instruction and positive valence after valence instruction; a right keypress indicated lack of self-descriptiveness or negative valence. Practice trials were made up of six words not included in the experimental trial. Self and valence tasks were randomly interleaved, with equal numbers of positive and negative words per task (i.e., 25 positive and 25 negative words presented with self instruction; 25 positive and 25 negative words with valence instruction).

Stimuli were presented in the center of the black screen in light gray Arial font, with a font size of 30 (for the instructions) and 48 (for the words). Each trial had the following sequence: One of two task instructions (self or valence instruction) would appear on the screen for 1,500 msec, followed by a fixation cross for $300 \mathrm{msec}$ and subsequent word display for 4,000 msec. Finally, during an intertrial interval of 2,000 msec, a fixation cross was shown again. Dependent variables were the proportions of judged words and reaction times (RTs).

Lexical decision task. In this task, participants were presented with all 100 words shown in the judgment task and 100 new words ( 50 positive, 50 negative). The 200 nonword letter strings were also presented. Participants were asked to judge each letter string as a word or a nonword. Speed and accuracy were emphasized equally. A left keypress indicated a word and a right keypress indicated a nonword. Practice trials were made up of six words and three nonwords. None of them were included in the experimental trial. Each trial had the following sequence: A fixation cross would appear for $1,000 \mathrm{msec}$, followed by a $150-\mathrm{msec}$ presentation of the letter string, after which the participant had to respond. We chose such limited exposure to the stimuli in the lexical decision task to limit deliberate, controlled processes that might contribute to RT biases. Furthermore, this procedure reduced potential effects of repeated word presentation on later explicit memory performance. Although our implicit memory task may still be prone to some contaminating effects from explicit memory (e.g., Verfaellie, Cermak, Letourneau, $\&$ Zuffante, 1991) when priming is measured with a lexical decision task (i.e., as compared with word-fragment completion), such influences are usually considered minimal (Goshen-Gottstein \& Moscovitch, 1995; Kellogg, Newcombe, Kammer, \& Schmitt, 1996). We therefore consider our lexical task to be a close approximation of an implicit memory test, although we acknowledge that it is not process-pure.

The dependent variables in the implicit memory task were RTs.

Free recall. After completion of the lexical decision task, participants were asked to write down on a sheet of paper, in any order, as many of the words as they could remember from any of the previous tasks. Participants were given 5 min to complete this task. Dependent variables were the proportions of recalled words. 


\section{Procedure}

The study was conducted at the Department of Psychology, University of Toronto, in an experimental room equipped with four computers, each with 19-in. screens. Participants were tested in small groups of 4, maximum. The task order was fixed for each participant: (1) judgment task, (2) lexical decision task, (3) free recall, (4) recognition (not reported here), (5) questionnaires. This fixed order was chosen to minimize influences of the questionnaires on the memory measures and contamination between memory measures. After initial encoding in the judgment task, lexical decision was administered so that participants remained unaware that their memory was being tested. Half of the participants completed the TMAS questionnaire first, followed by the BIDR questionnaire; the other half of the participants completed them in the reverse order. Finally, participants were thanked for their cooperation and fully debriefed.

\section{RESULTS}

\section{Statistical Analyses}

To provide a fine-grained analysis of encoding-related differences in all four groups of participants, we first analyzed RTs during the judgment task with a mixed-design ANOVA, with valence (positive/negative) and condition (self instruction/valence instruction) as repeated measures and trait anxiety (low/high), trait defensiveness (low/ high), and gender (female/male) as between-subjects factors. This allowed us to investigate whether the interaction of anxiety and defensiveness (i.e., the repressive coping style) influenced judgment of the materials over and above anxiety or defensiveness alone. In the subsequent analyses, the dependent variables were implicit and explicit memory performance (priming [RTs] in the lexical decision task, proportion of words recalled in free recall), again analyzed with mixed-design ANOVAs with the repeated measures valence and condition (two levels in implicit memory: self instruction/valence instruction; three levels in free recall: self instruction/valence instruction/ lexical decision task), and the between-subjects factors anxiety, defensiveness, and gender. Memory performance for words from the self instruction only were then each analyzed with mixed-design ANOVAs with valence and response (self-descriptive/not self-descriptive) as withinsubjects factors and anxiety, defensiveness, and gender as between-subjects factors. Memory performance in the latter analyses was calculated as proportions of words identified in priming or recalled in free recall, relative to each individual's total of negative and positive self-descriptive or not-self-descriptive words from the judgment task (possible maximum of 25 negative and 25 positive words).

RTs either faster than $200 \mathrm{msec}$ or more than 3 standard deviations above the individual's average RT were deleted. In the lexical decision task, priming was measured as the amount of time required to identify new words minus the time required to identify old words. Collapsed across factor levels, all dependent variables were normally distributed, assessed with Kolmogorov-Smirnov tests. Our statistical significance level was set to $p<.05$.

\section{Judgment Task}

Since the judgment task served as the basis for all following analyses, we first needed to ensure that groups of repressors and nonrepressors had equivalent RTs to words from the self instruction and the valence instruction. Thus, we first analyzed RTs in the judgment task. A main effect for condition $\left[F(1,95)=6.18, \eta_{\mathrm{p}}^{2}=.06\right]$ indicated longer RTs to words presented with the valence instruction $(M=$ $1,764.4, S E=38.3)$ than to words presented with the self instruction $(M=1,684.8, S E=30.9)$. We did not observe any other significant main effects, interactions, or borderline significant trends. Thus, repressors and nonrepressors judged words similarly fast.

To compare later memory for emotional information with and without perceived self-relevance in repressors and nonrepressors, we then analyzed the words from the self instruction separately. Dependent variable was the proportion of words endorsed or rejected as selfdescriptive in the self instruction. As described above, this mixed-design ANOVA had valence and response as repeated measures and anxiety, defensiveness, and gender as between-subjects factors. We found a significant interaction between valence and response $[F(1,95)=$ $\left.410.5, p<.001, \eta_{\mathrm{p}}^{2}=.81\right]$, indicating more positive words endorsed as self-descriptive and more negative words rejected as self-descriptive. The interaction between valence and response was qualified by two separate three-way interactions with anxiety $[F(1,95)=8.24$, $\left.p<.01, \eta_{\mathrm{p}}^{2}=.08\right]$ and defensiveness $[F(1,95)=6.17$, $\left.p<.05, \eta_{\mathrm{p}}^{2}=.06\right]$. No further main effects, interactions, or borderline significant effects were observed. Simple effects revealed that high levels of anxiety and low levels of defensiveness led to greater endorsing of negative words [anxiety, $t(101)=3.81, p<.001$; defensiveness, $t(101)=-4.25, p<.001]$ and greater rejecting of positive words as self-descriptive [anxiety, $t(101)=-2.23$, $p<.05$; defensiveness, $t(101)=2.4, p<.05]$. Note that there was no interaction between defensiveness and anxiety; low anxiety and high defensiveness alone contributed to a more positive self-view (see Table 1). Thus, although repressors had numerically the smallest number of self-relevant negative words and the highest number of self-relevant positive words, their judgments were similar to the other high-defensive or low-anxious groups.

Possibly, repressors simply paid less attention to undesirable information presented with the self instruction. If this were the case, we would expect shorter RTs in repressors than in nonrepressors when judging negative words as self-relevant (or positive words as not self-relevant). In order to rule out this possibility, we conducted an additional ANOVA on RTs to the words presented with self instruction, again with valence and response as repeated measures and anxiety, defensiveness, and gender as between-subjects factors. A significant two-way interaction of valence and response $[F(1,87)=95.24, p<.001$, $\left.\eta_{\mathrm{p}}^{2}=.52\right]$ was found, indicating shorter RTs to positive words judged self-descriptive than to those judged not self-descriptive $[t(96)=-10.18, p<.001]$ and complementary, longer RTs to negative self-descriptive words than to negative not-self-descriptive words $[t(100)=$ $6.32, p<.001]$. This tendency was not further qualified by anxiety or defensiveness or their interaction. Thus, im- 
Table 1

Proportions of Judged Words and Corresponding Reaction Times (in Milliseconds) During the Self Instruction in the Judgment Task

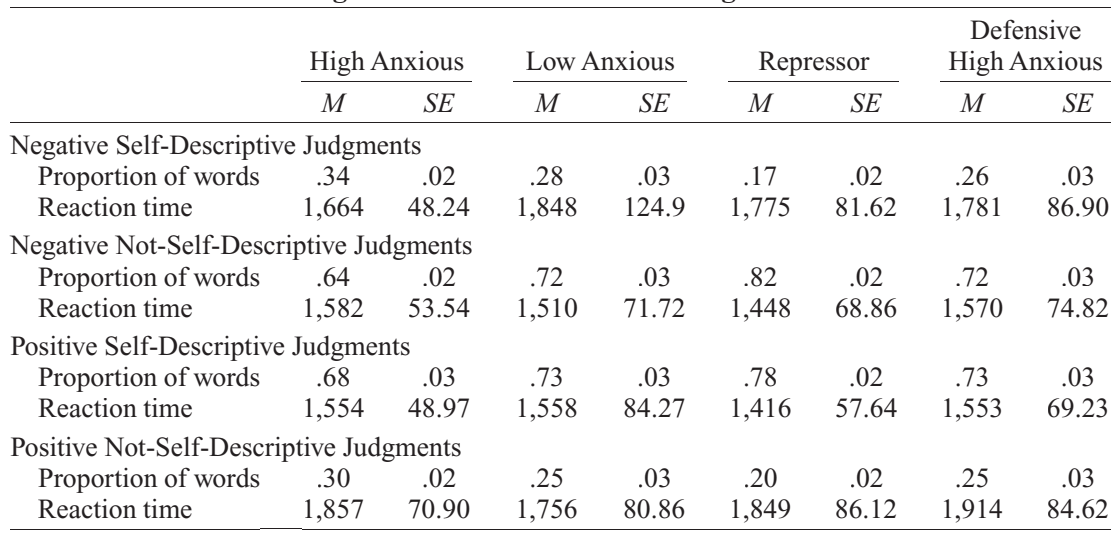

portantly, repressors did not simply disregard unfavorable characteristics, as would have been indicated by reduced RTs to unfavorable words (see Table 1).

In summary, participants were overall faster to make self-referential judgments than to make valence decisions. They judged themselves more positively than negatively, with low-anxious and high self-defensive individuals showing the most pronounced positivity. Participant groups required about the same time to make selfrelevance judgments and, thus, attention to self-relevant and -irrelevant words was similar across groups.

\section{Lexical Decision Task}

To determine whether implicit memory in repressors and groups of nonrepressors was influenced by the encoding task, we first submitted priming performance to an ANOVA with valence and condition as repeated measures and anxiety, defensiveness, and gender as betweensubjects factors. We obtained no main effects or interactions in this analysis.

Then, to address whether implicit memory was influenced by prior endorsement, we examined priming in the lexical decision task as a function of self-descriptiveness from the judgment task. We examined whether repressors would show less priming for negative self-descriptive words than nonrepressors would, demonstrating that repressive coping style lowers implicit memory. For this purpose, we submitted priming performance for words from the self instruction to a further ANOVA, with valence and response as repeated measures and anxiety, defensiveness, and gender as between-subjects factors (see Figure 1). We found a main effect for response $[F(1,87)=16.27, p<$ $\left..001, \eta_{\mathrm{p}}^{2}=.16\right]$, with better priming for words previously judged self-descriptive than for those previously judged not self-descriptive $[t(94)=-3.72, p<.001]$ — that is, an overall effect of self-relevance in implicit memory. Furthermore, a number of significant three-way interactions were observed, all qualified by a significant four-way interaction between response, valence, anxiety, and defensiveness $\left[F(1,87)=6.79, p<.05, \eta_{\mathrm{p}}^{2}=.07\right]$. Since the interaction between anxiety and defensiveness indicated possible differences between repressors and nonrepressors, we followed up on these between-subjects effects. We found that repressors had significantly less priming than all other groups for positive not-self-descriptive words [high anxious, $t(60)=-2.98, p<.01$; low anxious, $t(48)=-2.14, p<.05$; defensive high anxious, $t(45)=-2.75, p<.01] .^{2}$

Overall then, endorsing words as self-descriptive was associated with better implicit memory in all participant groups. Repressors and nonrepressors showed similar priming to negative words presented with self or valence instruction as well as to negative self-descriptive and notself-descriptive words, indicating no implicit memory reductions for negative information due to repressive coping style. However, only repressors showed significantly less priming for positive not-self-descriptive words.

\section{Free Recall}

As we did in the lexical decision task analysis, to first establish whether explicit memory in repressors and nonrepressors was influenced by encoding task, we submitted free recall performance to an ANOVA with valence and condition (self instruction/valence instruction/lexical decision task) as repeated measures and anxiety, defensiveness, and gender as between-subjects factors. We obtained a main effect for condition $\left[F(2,95)=150.21, p<.001, \eta_{\mathrm{p}}^{2}=.6\right]$ indicating a self-reference effect, with better free recall of words that were previously judged with self-reference than with words judged with regard to valence $[t(102)=$ $4.88, p<.001]$. Words presented with self instruction or valence instruction were better recalled than words that were shown only in the lexical decision task $[t(102)=$ $19.37, p<.001$, and $t(102)=16.71, p<.001$, respectively]. We further observed an interaction of valence and defensiveness $\left[F(2,95)=7.0, p<.01, \eta_{\mathrm{p}}^{2}=.07\right]$. Highdefensive individuals recalled slightly more positive words than negative words $[t(50)=2.54, p<.05]$, a pattern not observed in low-defensive individuals $[t(51)=$ $-1.62, p>.1]$. Thus, free recall was characterized by a 


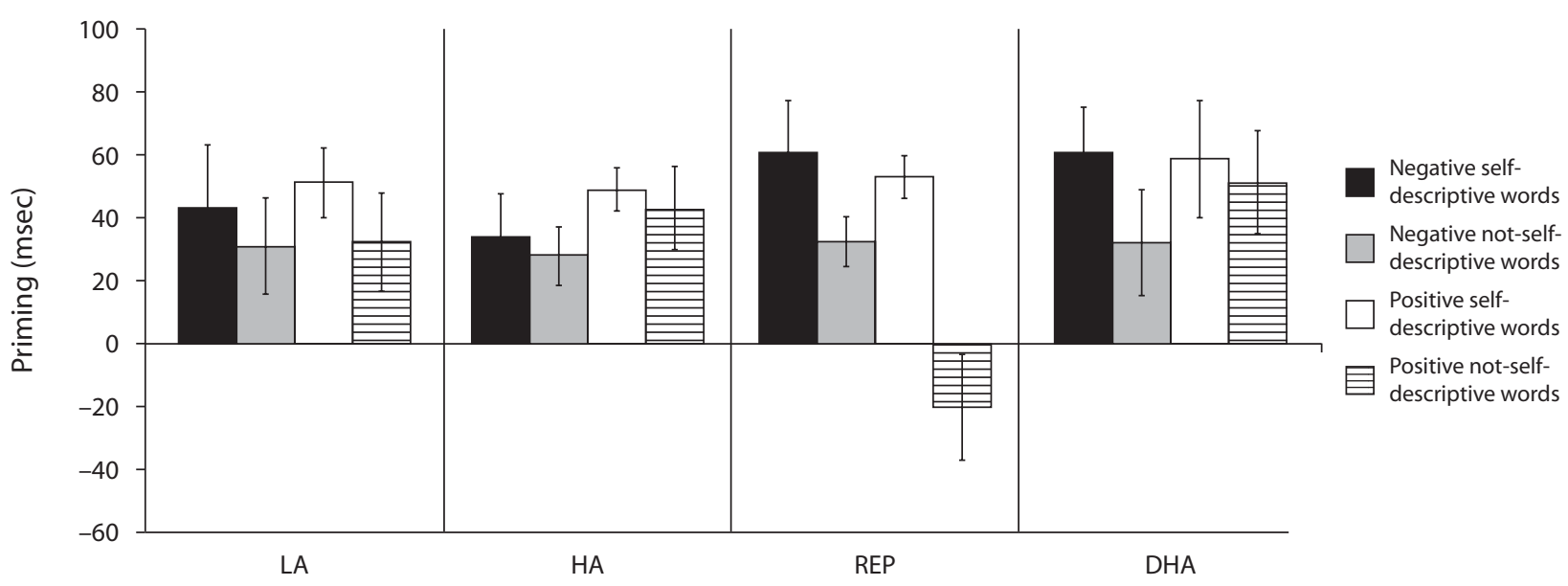

Figure 1. Priming in the lexical decision task as a function of valence, prior response in the judgment task, and the four participant groups. Identification time to old words was subtracted from identification time to newly presented words. Positive values indicate priming - that is, faster responses to old compared with new words. LA, low anxious; HA, high anxious; REP, repressor; DHA, defensive high anxious. Error bars are standard errors of the means.

self-reference effect, with better recall for words evaluated with reference to oneself than with reference to a semantic judgment. Furthermore, high-defensive individuals were selectively better in recalling positive than negative words.

To then examine potential effects of self-relevance in repressors and groups of nonrepressors in free recall, paralleling the analysis of the lexical decision task, we submitted proportions of freely recalled words judged in the self instruction to an ANOVA with valence and response as repeated measures and anxiety, defensiveness, and gender as between-subjects factors (see Figure 2). We anticipated that repressors show selectively lower free recall of negative self-relevant information.

Significant results were main effects of response $\left[F(1,87)=15.51, p<.001, \eta_{\mathrm{p}}^{2}=.15\right]$ and a four-way interaction of valence, response, anxiety, and defensiveness $\left[F(1,87)=6.71, p<.05, \eta_{\mathrm{p}}^{2}=.07\right.$; see Figure 2]. The main effect for response indicated an effect of selfdescriptiveness: better free recall of self-descriptive words than of not self-descriptive words. Follow-up tests of the differences driving the four-way interaction showed a recall advantage for negative self-descriptive words in all three groups of nonrepressors in comparison with negative not-self-descriptive words [high anxious, $t(31)=$ $3.01, p<.01$; low anxious, $t(19)=2.76, p<.05$; defensive high anxious, $t(16)=3.41, p<.01]$ as well as relative to positive self-descriptive words [low anxious, $t(19)=2.94, p<.01$; defensive high anxious, $t(16)=$ $2.71, p<.05]$ and marginally so in high anxious $[t(31)=$ $1.95, p=.06]$. By contrast, repressors did not show this recall advantage for negative self-descriptive words relative to negative not-self-descriptive words $[t(31)=0.89$, $p>1$ ], or when compared with positive self-descriptive words $[t(31)=-0.81, p>.1]$. Thus, repressors did not exhibit better recall of negative self-relevant information, which was seen in all groups of nonrepressors.

\section{Relationship Between Implicit and Explicit Memory Measures}

Since implicit memory testing always preceded explicit memory, one may argue that the explicit memory measures were contaminated by performance in the lexical decision task. In order to rule out this possibility, we correlated priming for negative self-descriptive words in the lexical decision task with later free recall for the same information in all four groups. The correlation coefficients ranged from $r=-.27$ to $r=.28$, and none reached significance. Thus, implicit memory for negative self-descriptive information was not significantly related to explicit memory in any of the groups and can be viewed as largely uncontaminated despite our fixed sequence of tasks.

\section{DISCUSSION}

Individuals differ in how they respond to emotional events and control the processing of emotional information. Using the repressive coping style as an example of high dispositional control, we found that repressors have highly selective memory reductions for negative, selfrelevant information. Thus, some individuals may downregulate their explicit memory for negative events that are perceived as being most self-relevant, in a pattern opposite to that expected as a result of the normative influences of emotion and self-relevance on memory. Such memory regulation was evident in free recall and absent in implicit memory. This suggests that repressors' regulation of memory originates from a retrieval-based late processing bias against personally undesirable information in the face of intact initial encoding.

We found self-reference effects, similar to those found in previous studies, in free recall but not in priming (cf. Symons \& Johnson, 1997). These effects were comparable in repressors and nonrepressors. However, when subjective self-relevance was taken into account, differences 


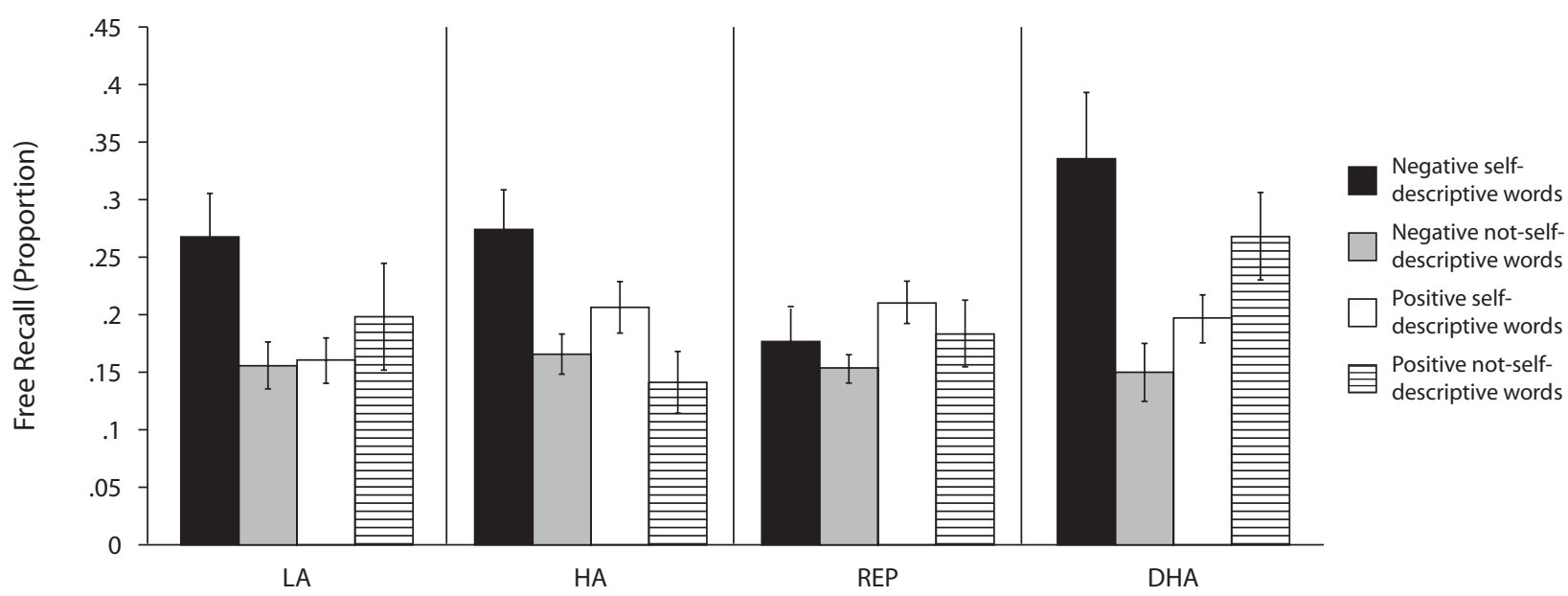

Figure 2. Proportion of remembered words in free recall as a function of emotional valence, prior response in the judgment task, and the four participant groups. LA, low anxious; HA, high anxious; REP, repressor; DHA, defensive high anxious. Error bars are standard errors of the means.

between repressors and nonrepressors became apparent: Nonrepressors showed better recall of negative words they had judged self-relevant. Thus, they showed better explicit memory for negative information encoded as related to salient aspects of their self-representation (Bellezza, 1984; Kuiper \& Rogers, 1979; Rogers, Kuiper, \& Kirker, 1977). In contrast, repressors were the only group that had no free recall advantage for negative self-relevant information. Repressors and nonrepressors had similarly prolonged responses when making self-relevance judgments to negative words, indicating equivalent encoding times across groups. More time for inspection would normally lead to deeper encoding and consequently enhanced later memory. This was only seen in the nonrepressor groups. Thus, even despite the fact that repressors spent as much time as nonrepressors encoding negative self-relevant information, repressors still displayed reduced later explicit memory for these items. Furthermore, repressors made fewer self-relevance judgments to negative words than the other groups, rendering this word category even more unique and distinct than in nonrepressors. This normally also leads to proportionately better memory (list-length effect, Murdock [1962]; von Restorff effect, von Restorff [1933]); however, repressors recalled these items less. Therefore, their reduced recall of these items is all the more striking.

Emotion can both enhance and impair memory (e.g., A. K. Anderson, Wais, \& Gabrieli, 2006; Hurlemann et al., 2005; Miu, Heilman, Opre, \& Miclea, 2005; Strange, Hurlemann, \& Dolan, 2003) and this dissociation has been linked to the degree of strategic control during retrieval. For instance, Depue, Banich, and Curran (2006) showed that effects of voluntary memory suppression are larger for emotional than for neutral stimuli. Thus, people do not just remember emotional items better, but they could also forget them more easily. Our results suggest that when strategic control of memory retrieval is difficult (i.e., in implicit memory), the capacity for repressors to reduce negative self-relevant memories was disrupted.
These results suggest a potential overlap in the neural mechanisms between naturally occurring forgetting and voluntary (emotional) memory suppression (M. C. Anderson et al., 2004; Depue et al., 2007). Our findings challenge our alternate hypothesis that expertise in memory forgetting (repressiveness) may render suppression more involuntary and less strategic. Similar retrieval-based prefrontal mechanisms may be involved in instructed and naturally occurring forgetting. This emphasizes the validity and generalizability of voluntary memory suppression accounts to specialized populations who more regularly practice down-regulation of memory.

Nevertheless, early processing differences between repressors and nonrepressors have been reported (e.g., Bonanno, Davis, Singer, \& Schwartz, 1991; Calvo \& Eysenck, 2000; Fox, 1994; Hansen \& Hansen, 1988; Myers \& McKenna, 1996; Newman \& McKinney, 2002; Rauch et al., 2007). Our findings suggest that these cannot be related to later memory in a straightforward manner (i.e., less attention/brain activity at encoding leading to lower later memory). One possibility for this divergence is that our encoding task required participants to closely pay attention and make a deliberate decision to stimuli that could be avoided with less direct encoding instructions. Consistent with this notion, many of the studies finding early encoding-related differences either allowed participants to not attend to the materials (Rauch et al., 2007), or even explicitly asked participants to ignore them (Bonanno et al., 1991; Fox, 1994; Hansen \& Hansen, 1988; Myers \& McKenna, 1996; Newman \& McKinney, 2002).

A few remarks should be given here to address potential problems with our implicit-explicit memory dissociation: Since implicit memory was always tested before explicit memory and words had been presented twice before explicit memory testing, but only once before implicit memory testing, one may argue that effects of repressive coping only became visible after some delay and/or due to repeated exposure. For the following reasons, we believe these possibilities are unlikely. First, we observed no significant 
correlations between priming and free recall in any of the groups, indicating little if any systematic contamination between the measures. Repetition effects on explicit memory were minimized by employing short exposure times in the lexical decision task. ${ }^{3}$ Furthermore, although our paradigm used different delays between implicit and explicit memory tests, expression of repetition priming is usually unaffected by such delays (see Schacter, 1987). Finally, one may argue that the results of implicit memory tasks are generally less reliable than those of explicit memory tasks (e.g., Meier \& Perrig, 2000). However, we also observed, similar to better free recall of self-relevant words, better priming for self-relevant words in comparison with nonrelevant words. The magnitude of these effects was almost identical in priming and free recall (priming, $\eta_{\mathrm{p}}^{2}=.16$; free recall, $\left.\eta_{\mathrm{p}}^{2}=.15\right)$, arguing against a selective insensitivity of the implicit memory task.

We observed one unexpected result in our implicit memory task. Repressors, but no other group, showed no priming for positive, not-self-relevant words. We can only speculate on the mechanisms driving this result: Possibly, positive words previously judged not self-descriptive still retained their generally positive meaning. However, because they were judged as not self-descriptive, their connotation became negative. Of all groups, only repressors may have become sensitive to this conflict between a generally positive, but momentarily negative meaning of a word. This conflict may have prolonged their lexical decision times. This interpretation matches with repressors' previously reported increased dwell times when confronted with emotionally ambiguous information (cf. Hansen \& Hansen, 1988; Hock \& Krohne, 2004).

Our implicit-explicit memory dissociation parallels previously reported physiological-psychological dissociations of objective and subjective emotional arousal. A number of studies reported discrepancies between low self-reported anxiety and autonomic measures indicating objectively high physiological arousal in repressors (Asendorpf \& Scherer, 1983; Barger, Kircher, \& Croyle, 1997; Derakshan \& Eysenck, 2001; Newton \& Contrada, 1992; Pauls \& Stemmler, 2003; Weinberger et al., 1979). This similarity between findings in memory and emotion studies implies that the explicitness with which sensitive information is asked for reduces both repressors' emotional experience and memory. Similarly, patients with psychogenic amnesia show dissociations between implicitly accessible memories despite overt retrieval failure (Fujiwara et al., 2008).

In future studies, repressors' brain activity during selfreferential processing may be a good place to search for the neural basis of memory reductions in this population. Cortical midline regions are commonly activated during self-referential processing (e.g., medial prefrontal cortex, posterior cingulate cortex; Johnson et al., 2002; Kelley et al., 2002; Northoff et al., 2006). Macrae, Moran, Heatherton, Banfield, and Kelley (2004) observed medial prefrontal cortex activity to be strongest when people endorsed information as self-descriptive and to be predictive of later memory. Thus, in unselected samples of participants, medial prefrontal activity is a critical component of memory formation when the information elicits self-reflection. Repressors' brain activity during self-referential processing may be less related to later memory than that of nonrepressors. Such a pattern would challenge our retrieval-based interpretation. For example, even if attention to negative self-referential information is equivalent in repressors and nonrepressors, the quality and depth of self-referential encoding (i.e., engagement of cortical midline, medial PFC structures) may differ. This may result in or even aid later memory reductions in repressors. For this purpose, it may be worthwhile to consider a subsequent memory paradigm, ideally using continuous ratings of self-relevance rather than simple yes/no judgments, as a parametric measure of self-relevance (and possible involvement of medial prefrontal brain regions). Self-relevance and associated medial PFC activity could then be related to later memory success or failure in nonrepressors and repressors.

As recently pointed out by Haas and Canli (2008), facilitation of emotional memory is subject to a variety of personality characteristics. In some individuals-for example, those scoring high in neuroticism (Haas, Omura, Constable, \& Canli, 2007) or extraversion (Canli, Sivers, Whitfield, Gotlib, \& Gabrieli, 2002)—increased amygdala/anterior cingulate sensitivity in response to emotional information may promote deeper encoding and later retrieval facilitation. In addition to identifying such emotional vulnerability markers for excessive emotional memory, future neuroimaging studies of repressors as counterexamples of emotional and self-related memory inhibition may reveal important complementary insights into the control of mood-related pathologies.

\section{AUTHOR NOTE}

We gratefully thank Vanessa Au, James J. Kim, Kaitlin Laidlaw, and Tina Simic for their help with participant testing. Correspondence concerning this article should be addressed to E. Fujiwara, University of Alberta, Department of Psychiatry, Walter Mackenzie Centre, Room 1E1, Edmonton, AB, T6G 2R7 Canada (e-mail: efujiwara@ualberta.ca).

\section{REFERENCES}

Anderson, A. K., Wais, P. E., \& Gabrieli, J. D. E. (2006). Emotion enhances remembrance of neutral events past. Proceedings of the $\mathrm{Na}$ tional Academy of Sciences, 103, 1599-1604.

Anderson, M. C., \& Green, C. (2001). Suppressing unwanted memories by executive control. Nature, 410, 366-369.

Anderson, M. C., Ochsner, K. N., Kuhl, B., Cooper, J., Robertson, E., GABrieli, S. W., ET AL. (2004). Neural systems underlying the suppression of unwanted memories. Science, 303, 232-235.

ANDERSON, N. H. (1968). Likableness ratings of 555 personality-trait words. Journal of Personality \& Social Psychology, 9, 272-279.

Asendorpf, J. B., \& Scherer, K. R. (1983). The discrepant repressor: Differentiation between low anxiety, high anxiety, and repression of anxiety by autonomic-facial-verbal patterns of behavior. Journal of Personality \& Social Psychology, 45, 1334-1346.

Ashley, A., \& Holtgraves, T. (2003). Repressors and memory: Effects of self-deception, impression management, and mood. Journal of Research in Personality, 37, 284-296.

Barger, S. D., Kircher, J. C., \& Croyle, R. T. (1997). The effects of social context and defensiveness on the physiological responses of repressive copers. Journal of Personality \& Social Psychology, 73, 1118-1128.

Bellezza, F. S. (1984). The self as a mnemonic device: The role of internal cues. Journal of Personality \& Social Psychology, 47, 506-516. 
Bendig, A. W. (1956). The development of a short form of the Manifest Anxiety Scale. Journal of Consulting Psychology, 20, 384.

Bonanno, G. A., Davis, P. J., Singer, J. L., \& Schwartz, G. E. (1991). The repressor personality and avoidant information processing: A dichotic listening study. Journal of Research in Personality, 25, 386-401

Buckner, R. L., \& KoutstaAl, W. (1998). Functional neuroimaging studies of encoding, priming, and explicit memory retrieval. Proceedings of the National Academy of Sciences, 95, 891-898.

CALVo, M. G., \& EYSENCK, M. W. (2000). Early vigilance and late avoidance of threat processing: Repressive coping versus high/low anxiety. Cognition \& Emotion, 14, 763-787.

Canli, T., Sivers, H., Whitfield, S. L., Gotlib, I. H., \& Gabrieli, J. D. E. (2002). Amygdala response to happy faces as a function of extraversion. Science, 296, 2191.

Crowne, D. P., \& Marlowe, D. (1964). The approval motive. New York: Wiley.

Davis, P. J. (1990). Repression and the inaccessibility of emotional memory. In J. L. Singer (Ed.), Repression and dissociation (pp. 387-434). Chicago: Chicago University Press.

Davis, P. J., \& Schwartz, G. E. (1987). Repression and the inaccessibility of affective memories. Journal of Personality \& Social Psychology, 52, 155-162.

Depue, B. E., Banich, M. T., \& Curran, T. (2006). Suppression of emotional and nonemotional content in memory: Effects of repetition on cognitive control. Psychological Science, 17, 441-447.

Depue, B. E., Curran, T., \& Banich, M. T. (2007). Prefrontal regions orchestrate suppression of emotional memories via a two-phase process. Science, 317, 215-219.

Derakshan, N., \& Eysenck, M. W. (2001). Effects of focus of attention on physiological, behavioural, and reported state anxiety in repressors, low-anxious, high-anxious, and defensive high-anxious individuals. Anxiety, Stress, \& Coping, 14, 285-299.

Fox, E. (1994). Attentional bias in anxiety-A defective inhibition hypothesis. Cognition \& Emotion, 8, 165-195.

Freud, S. (1957). Repression. In J. Strachey (Ed.), The standard edition of the complete psychological works of Sigmund Freud (Vol. 14). London: Hogarth Press. (Originally published in 1915)

Fujiwara, E., Brand, M., Kracht, L., Kessler, J., Diebel, A., Netz, J., \& Markowitsch, H. J. (2008). Functional retrograde amnesia: A multiple case study. Cortex, 44, 29-45.

Goshen-Gottstein, Y., \& Moscovitch, M. (1995). Repetition priming effects for newly formed associations are perceptually based: Evidence from shallow encoding and format specificity. Journal of Experimental Psychology: Learning, Memory, \& Cognition, 21, 1249-1262.

HAAS, B. W., \& CANLI, T. (2008). Emotional memory function, personality structure and psychopathology: A neural system approach to the identification of vulnerability markers. Brain Research Reviews, 58, 74-81.

HaAs, B. W., Omura, K., Constable, R. T., \& Canli, T. (2007). Emotional conflict and neuroticism: Personality-dependent activation in the amygdala and subgenual anterior cingulate. Behavioral Neuroscience, 121, 249-256.

Hansen, R. D., \& Hansen, C. H. (1988). Repression of emotionally tagged memories: The architecture of less complex emotions. Journal of Personality \& Social Psychology, 55, 811-818.

Hock, M., \& Krohne, H. W. (2004). Coping with threat and memory for ambiguous information: Testing the repressive discontinuity hypothesis. Emotion, 4, 65-86.

Holtgraves, T., \& Hall, R. (1995). Repressors-What do they repress and how do they repress it? Journal of Research in Personality, 29, 306-317.

Hurlemann, R., Hawellek, B., Matusch, A., Kolsch, H., WolLERSEN, H., MADEA, B., ET AL. (2005). Noradrenergic modulation of emotion-induced forgetting and remembering. Journal of Neuroscience, 25, 6343-6349.

Ioannou, M. C., MogG, K., \& Bradley, B. P. (2004). Vigilance for threat: Effects of anxiety and defensiveness. Personality \& Individual Differences, 36, 1879-1891.

JANSSON, B., LundH, L.-G., \& OLdENBuRG, C. (2005). Is defensiveness associated with cognitive bias away from emotional information? Personality \& Individual Differences, 39, 1373-1382.
Johnson, S. C., Baxter, L. C., Wilder, L. S., Pipe, J. G., Heiserman, J. E., \& Prigatano, G. P. (2002). Neural correlates of self-reflection. Brain, 125, 1808-1814.

Kelley, W. M., Macrae, C. N., Wyland, C. L., Caglar, S., Inati, S., \& Heatherton, T. F. (2002). Finding the self? An event-related fMRI study. Journal of Cognitive Neuroscience, 14, 785-794.

Kellogg, R. T., Newcombe, C., Kammer, D., \& Schmitt, K. (1996). Attention in direct and indirect memory tasks with short- and longterm probes. American Journal of Psychology, 109, 205-217.

Kuiper, N. A., \& Rogers, T. B. (1979). Encoding of personal information: Self-other differences. Journal of Personality \& Social Psychology, 37, 499-514.

Macrae, C. N., Moran, J. M., Heatherton, T. F., Banfield, J. F., \& Kelley, W. M. (2004). Medial prefrontal activity predicts memory for self. Cerebral Cortex, 14, 647-654.

Meier, B., \& Perrig, W. J. (2000). Low reliability of perceptual priming: Consequences for the interpretation of functional dissociations between explicit and implicit memory. Quarterly Journal of Experimental Psychology, 53A, 211-233.

Mendolia, M. (2002). An index of self-regulation of emotion and the study of repression in social contexts that threaten or do not threaten self-concept. Emotion, 2, 215-232.

Miu, A. C., Heilman, R. M., Opre, A., \& Miclea, M. (2005). Emotioninduced retrograde amnesia and trait anxiety. Journal of Experimental Psychology: Learning, Memory, \& Cognition, 31, 1250-1257.

Murdock, B. B. (1962). The serial position effect of free recall. Journal of Experimental Psychology, 64, 482-488.

Myers, L. B., \& BrewIN, C. R. (1994). Recall of early experience and the repressive coping style. Journal of Abnormal Psychology, 103, 288-292.

Myers, L. B., Brewin, C. R., \& Power, M. J. (1998). Repressive coping and the directed forgetting of emotional material. Journal of Abnormal Psychology, 107, 141-148.

Myers, L. B., \& Derakshan, N. (2004). To forget or not to forget: What do repressors forget and when do they forget? Cognition \& Emotion, 18, 495-511.

Myers, L. B., \& McKenna, F. P. (1996). The colour naming of socially threatening words. Personality \& Individual Differences, 20, 801-803.

Newman, L. S., \& Hedberg, D. A. (1999). Repressive coping and the inaccessibility of negative autobiographical memories: Converging evidence. Personality \& Individual Differences, 27, 45-53.

Newman, L. S., \& McKinney, L. C. (2002). Repressive coping and threat-avoidance: An idiographic Stroop study. Personality \& Social Psychology Bulletin, 28, 409-422.

Newton, T. L., \& Contrada, R. J. (1992). Repressive coping and verbal-autonomic response dissociation: The influence of social context. Journal of Personality \& Social Psychology, 62, 159-167.

Northoff, G., Heinzel, A., De Greck, M., Bermpohl, F., DobroWOLNY, H., \& PANKSEPP, J. (2006). Self-referential processing in our brain-A meta-analysis of imaging studies on the self. NeuroImage, 31, 440-457.

Oldenburg, C., Lundh, L.-G., \& Kivisto, P. (2002). Explicit and implicit memory, trait anxiety, and repressive coping style. Personality \& Individual Differences, 32, 107-119.

Paulhus, D. L. (1991). Measurement and control of response bias. In J. P. Robinson, P. R. Shaver, \& L. S. Wrightsman (Eds.), Measures of personality and social psychological attitudes (pp. 17-59). San Diego: Academic Press.

Pauls, C. A., \& Stemmler, G. (2003). Repressive and defensive coping during fear and anger. Emotion, 3, 284-302.

Rauch, A. V., Ohrmann, P., Bauer, J., Kugel, H., Engelien, A., Arolt, V., ET AL. (2007). Cognitive coping style modulates neural responses to emotional faces in healthy humans: A 3-T fMRI study. Cerebral Cortex, 17, 2526-2535.

Rogers, T. B., Kuiper, N. A., \& Kirker, W. S. (1977). Self-reference and the encoding of personal information. Journal of Personality $\&$ Social Psychology, 35, 677-688.

SAnder, K., Roth, P., \& Scheich, H. (2003). Left-lateralized fMRI activation in the temporal lobe of high repressive women during the identification of sad prosodies. Cognitive Brain Research, 16, 441-456. 
SCHACTER, D. L. (1987). Implicit expressions of memory in organic amnesia: Learning of new facts and associations. Human Neurobiology, 6, 107-118.

Schimmack, U., \& Hartmann, K. (1997). Individual differences in the memory representation of emotional episodes: Exploring the cognitive processes in repression. Journal of Personality \& Social Psychology, 73, 1064-1079.

Shane, M., \& Peterson, J. B. (2004). Self-induced memory distortions and the allocation of processing resources at encoding and retrieval. Cognition \& Emotion, 18, 533-558.

Strange, B. A., Hurlemann, R., \& Dolan, R. J. (2003). An emotioninduced retrograde amnesia in humans is amygdala- and betaadrenergic-dependent. Proceedings of the National Academy of Sciences, 100, 13626-13631.

Symons, C. S., \& Johnson, B. T. (1997). The self-reference effect in memory: A meta-analysis. Psychological Bulletin, 121, 371-394.

Verfaellie, M., Cermak, L. S., Letourneau, L., \& Zuffante, P. (1991). Repetition effects in a lexical decision task: The role of episodic memory in the performance of alcoholic Korsakoff patients. Neuropsychologia, 29, 641-657.

vON RESTORFF, H. (1933). Über die Wirkung von Bereichsbildungen im Spurenfeld. Psychologische Forschung, 18, 299-234.

Weinberger, D. A. (1990). The construct validity of the repressive coping style. In J. L. Singer (Ed.), Repression and dissociation (pp. 337-386). Chicago: Chicago University Press.
Weinberger, D. A., Schwartz, G. E., \& Davidson, R. J. (1979). Lowanxious, high-anxious, and repressive coping styles: Psychometric patterns and behavioral and physiological responses to stress. Journal of Abnormal Psychology, 88, 369-380.

\section{NOTES}

1. Such cutoff scores can be avoided by employing a combined score of defensiveness and anxiety (cf. Mendolia, 2002). A reanalysis of our results with such index score and hierarchical regression analyses did not qualitatively change our results, but showed lowered statistical power in some of the analyses. Thus, for reasons of clarity, we present our results in the more conventional categorical fashion.

2. This unexpected effect of reduced priming for positive, not-selfdescriptive words in repressors was further qualified by an interaction with gender $[F(1,87)=11.88, p<.01]$. Although female and male repressors both exhibited longer latencies to positive, not-self-descriptive words, the difference from the other groups reached significance only in females. Male and female repressors and nonrepressors were otherwise identical in their priming performance.

3. This was indexed by near-floor levels of free recall for new words presented only during the lexical decision task.

(Manuscript received October 28, 2007; revision accepted for publication May 29, 2008.) 